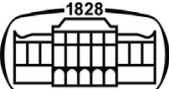

AKADÉMIAI KIADÓ

\title{
Sodium alginate and pectin estimation in raft forming pharmaceuticals by high performance liquid chromatography method
}

\section{Acta Chromatographica}

33 (2021) 2, 127-133

DOI:

$10.1556 / 1326.2020 .00765$

(c) 2020 The Author(s)

\section{ORIGINAL RESEARCH} PAPER

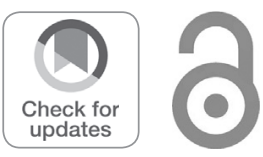

\author{
MUHAMMAD HANIF ${ }^{1}$, SHAHID SHAH ${ }^{2}$, NASIR RASOOL ${ }^{3}$, \\ GHULAM ABBAS $^{4 *} \odot$, MALIK SAADULLAH ${ }^{5}$, SAJID \\ MEHMOOD KHAN ${ }^{6}$, MUHAMMAD MASOOD AHMED ${ }^{1}$, \\ NAZAR ABBAS ${ }^{4}$, MEHRAN ASHFAQ $^{4}$ and OMEIRA IQBAL ${ }^{4}$
}

\footnotetext{
${ }^{1}$ Faculty of Pharmacy, Bahauddin Zakariya University Multan, Multan, Pakistan

${ }^{2}$ Department of Pharmacy Practice, Faculty of Pharmaceutical Sciences Government College University Faisalabad, Faisalabad, Pakistan

${ }^{3}$ Department of Chemistry, Government College University Faisalabad, Faisalabad, Pakistan

${ }^{4}$ Department of Pharmaceutics, Faculty of Pharmaceutical Sciences Government College University Faisalabad, Faisalabad, Pakistan

${ }^{5}$ Department of Pharmaceutical Chemistry, Faculty of Pharmaceutical Sciences Government College University Faisalabad, Faisalabad, Pakistan

${ }^{6}$ Faculty of Pharmacy and Alternative Medicines, The Islamia University Bahawalpur, Bahawalpur, Pakistan
}

Received: January 22, 2020 - Accepted: May 05, 2020

Published online: June 22, 2020

\begin{abstract}
The high performance liquid chromatographic (HPLC) method was developed for the combined estimation of sodium alginate and pectin in raft forming pharmaceuticals on $\mathrm{C}_{18}$ column ZORBAX ODS (1.5 $\mathrm{cm} \times 4.6 \mathrm{~mm}, 5 \mu \mathrm{m}$ ) with UV detection at $378 \mathrm{~nm}$. The assay condition comprised of phosphate buffer $\mathrm{pH} 7.4$ and methanol $60: 40 \% \mathrm{v} / \mathrm{v}$ at a flow rate of $1.25 \mathrm{~mL} / \mathrm{min}$. The separation of sodium alginate and pectin with good resolution and a retention time less than $8 \mathrm{~min}$ was attained. The method was linear over a range of $200-800 \mu \mathrm{g} / \mathrm{mL}$ of sodium alginate and pectin. The regression values obtained from linearity curve of sodium alginate and pectin were 0.9993 and 0.9991 , respectively. The retention time of sodium alginate and pectin was 3.931 and $7.470 \mathrm{~min}$, respectively. The percent recovery of sodium alginate and pectin ranged from $94.2-98.5 \%$ and $92.1-98.4 \%$ respectively. The limit of detection (LOD) and limit of quantification (LOQ) of sodium alginate were found to be 2.443 and $3.129 \mu \mathrm{g} / \mathrm{mL}$ and the LOD and LOQ of pectin were 3.126 and $3.785 \mu \mathrm{g} / \mathrm{mL}$, respectively. The resolution of sodium alginate and pectin was found in the range of 1.03-1.89 and 1.10-1.91, respectively. This method has been successfully applied to analyze the concentrations of sodium alginate and pectin in raft forming drug delivery systems.
\end{abstract}

\section{KEYWORDS}

Sodium alginate, pectin, raft, HPLC

\section{INTRODUCTION}

*Corresponding author E-mail: ghulamabbas@gcuf.edu.pk
Nowadays, polysaccharide based advanced and innovative pharmaceutical materials are preferred because of their natural abundance, easy accessibility, low cost, biodegradability, nontoxicity and furthermore, their sustainable nature has increased their requisition. The raft forming delivery system can incorporate a variety of biopolymers including sodium alginate and pectin etc. The physicochemical properties of sodium alginate, the sodium salt of alginic acid, indicate that this natural macromolecule is biodegradable, nontoxic and $\mathrm{pH}$ sensitive in 
nature; in addition, the $\mathrm{pH}$ sensitivity of the polymer makes it stable only in an acidic environment, while in alkaline media, rapid dissolution occurs, which leads to instability and limits its applications. Sodium alginate swells in water but typically produces an acid $\mathrm{pH}$ gel due to its protonation and can be crosslinked by the application of physical and chemical methods [1]. The chemical structure of alginate, as mentioned in Fig. 1, has a linear copolymer of 1, 4-glycosidically linked $\beta$ D-mannuronic acid and $\alpha$-L-guluronic acid. Pectin, illustrated in Fig. 1, is an abundantly available natural polysaccharide generally present in the cell wall of plants, while its structure is composed of uronic acid residues which are linked together by $\alpha$-1, 4-glycosidic bonds [2]. The pectin is favored in formulations due to its resistance property against certain enzymes such as amylase and protease but a disadvantage of the early drug release due to its hydrophilic nature cannot be overlooked. On the other hand, in contact with divalent cations, the pectin forms a gels radially.

The sodium alginate and pectin are extensively used in the raft forming formulations used for the management of reflux disorders of stomach. The stomach contents irritate the esophagus and raft prevent the entry of stomach contents into esophagus. The sodium alginate and pectin concentrations are important for the strength and resilience of raft that is developed in the stomach. Only one high performance liquid chromatographic (HPLC) method was available for the determination of sodium alginate [3] in drug delivery systems contained sodium alginate as polymeric material. To our best knowledge no method available for the combined estimation of alginate and pectin in raft forming pharmaceuticals.

\section{MATERIALS AND METHODS}

\section{Materials}

Sodium alginate and pectin were purchased from Sigma Aldrich Chemie Gmbh, Germany. Methanol and acetonitrile of HPLC grade were purchased from Sigma Aldrich Chemie Gmbh, Germany. Potassium dihydrogen phosphate and glacial acetic acid were purchased from BDH Wharf Road, London. The double distilled water was used throughout the
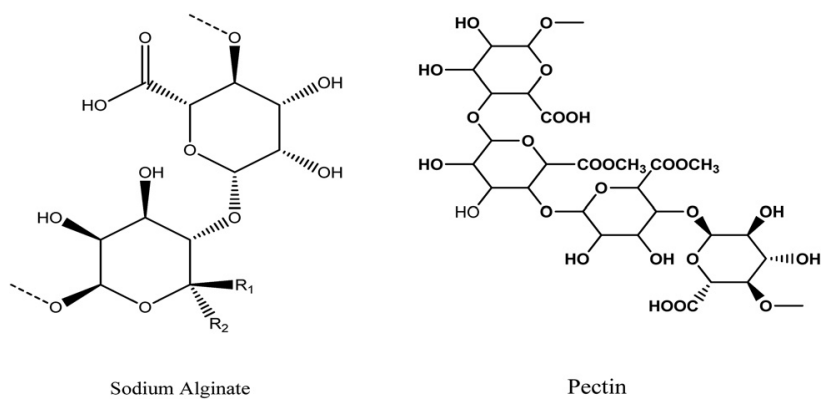

Fig. 1. Chemical structure of sodium alginate and pectin study and the other chemicals/reagents used were of analytical grade.

\section{Instrumentation}

HPLC system (PerkinElmer 710 Bridgeport avenue Shelton, Connecticut USA) fitted out with $\mathrm{C}_{18}$ column ZORBAX ODS $(1.5 \mathrm{~cm} \times 4.6 \mathrm{~mm}, 5 \mu \mathrm{m})$ Agilent technologies Santa Clara, California, United States. Analytical weighing balance model CB 6698, Sartorius Stedim, Germany, and pH meter model 370 Jenway UK. Cellulose acetate and cellulose nitrate filters $0.45 \mu \mathrm{m}$ Sartorius Stedim, Germany, used for filtration of solvents using filtration assembly (Sartorius Stedim, Germany). Membrane disc filters $0.22 \mu \mathrm{m}$ Millipore Bedford MA, United States.

\section{Preparation of mobile phases and chromatographic conditions}

The mobile phase was prepared by using methanol and phosphate buffer $\mathrm{pH} 7.4$ (40:60\% v/v). A $378 \mathrm{~nm}$ wavelength was selected as it gave reasonably high absorption for sodium alginate and pectin when used in proportions usually found in developed formulation. Using a UV detector at $378 \mathrm{~nm}$, the chromatographic conditions allow a resolution between sodium alginate and pectin with a reasonable time. A detection wavelength of $378 \mathrm{~nm}$ for sodium alginate and pectin were selected based on the full-range UV spectral data due to its high sensitivity for all related substances and a minimal difference in response factors. The mobile phase and sample solution were degassed by using sonicator (Branson Ultrasonic, USA) and filtered through $0.22 \mu \mathrm{m}$ filter. The flow rate of mobile phase was $1.25 \mathrm{~mL} / \mathrm{min}$ and detection of polymers were made at 378 $\mathrm{nm}$. Before injection of each sample solution, the HPLC system was equilibrated for $30 \mathrm{~min}$ with the mobile phase flowing throw the system.

\section{Standard solutions}

The primary stock standard solutions of $1,000 \mu \mathrm{g} / \mathrm{mL}$ sodium alginate and $1,000 \mu \mathrm{g} / \mathrm{mL}$ pectin were prepared in the mobile phase (methanol and phosphate buffer $\mathrm{pH} 7.4,40: 60 \% \mathrm{v} / \mathrm{v}$ ) and protected from light. The working solutions were prepared by diluting aliquots of stock solutions with mobile phase at 100, 200, 400, 600 and $800 \mu \mathrm{g} / \mathrm{mL}$ concentrations.

\section{VALIDATION OF METHOD}

\section{Analytical curve}

The relationship between the concentrations of sodium alginate and pectin and the response detector were determined by the analytical curve [4]. Stock solutions of 1,000 $\mu \mathrm{g} / \mathrm{mL}$ of sodium alginate and pectin were prepared in the mobile phase composed of phosphate buffer $\mathrm{pH} 7.4$ and methanol $(60: 40 \% \mathrm{v} / \mathrm{v})$. A series of serial dilutions such as 100 , 200, 400, 600 and $800 \mu \mathrm{g} / \mathrm{mL}$ solutions were made by using primary stock solutions of sodium alginate and pectin. These solutions were injected into the HPLC system for analysis after 
filtering through $0.22 \mu \mathrm{m}$ filters. The analytical curves of sodium alginate and pectin were constructed by plotting areas of peak verses concentration of polymers. The curves were used to calculate the regression data and the $R^{2}$ values.

\section{Selectivity}

The selectivity was studied by processing and evaluating blanks as well as the co-administered sodium alginate and pectin. The retention times of sodium alginate and pectin were determined under similar chromatographic conditions. Selectivity was calculated by matching the chromatograms of six repeated injections of each blank with the standard polymer solution.

\section{Precision and accuracy}

The precision of the developed method establishes the proximity of agreement between a sequences of measurements obtained from several sampling of the same identical sample, while the accuracy of the method defines the nearness of the results obtained by the method with the true value of the analyte [5]. The precision of the method was assessed by calculating the RSD at three concentration levels (200, 400 and $600 \mu \mathrm{g} / \mathrm{mL}$ ). Within-day precision was assessed by five repeated measurements for each concentration of sodium alginate and pectin, while between day precision was assessed by duplicate measurements of freshly prepared samples during a period of 5 consecutive days. The accuracy of the developed method was expressed as the percentage recovery and was valued by associating the peak area of samples that comprise a known quantity of sodium alginate and pectin to the peak area of the standard solutions spiked with the same amount.

\section{Detection and quantification limits}

The limit of detection (LOD) was the lowermost concentration level of the sodium alginate and pectin which can be detected but not essentially quantified and was calculated using the sigma method while the limit of quantification (LOQ) was the lowest concentration of sodium alginate and pectin in the sample that could be measured by the detector with appropriate precision and accuracy [6].

\section{System suitability test}

The suitability [7] of system was assessed with the composition of mobile phase, followed by 6 injections of the same standard. These 6 continuous injections were used to assess the system suitability each day of method validation. The features verified were the retention time, tailing factor, peak area, theoretical plates and resolution. The chromatographic resolution is the difference in retention time between two adjacent peaks divided by the average width of the peaks.

\section{Preparation of raft forming tablets}

The tablets were prepared by the wet granulation method [8]. First, the polymers and other excipients were mixed thoroughly and passed through an 18-mesh screen as mentioned in Table 1, then the powder mixture of polymer and other excipients passed the micromeritic limits was mixed using a sigma mixer. Second, the powder mixture was granulated using $2 \%(w / w)$ (hydroxypropyl methyl cellulose) HPMC E5 in a $90 \%$ ethanol solution. Finally, the granules were dried at $40{ }^{\circ} \mathrm{C}$ for $2 \mathrm{~h}$, passed through an 18-mesh screen and compressed using a minipress MII (Pharma Test, Hainburg, Germany).

\section{Estimation of alginate and pectin contents within the raft}

Simulated gastric fluid (SGF) $150 \mathrm{~mL}$ was taken in a beaker with $250 \mathrm{~mL}$ carrying capacity and the temperature was maintained at $37^{\circ} \mathrm{C}$ using hot plate stirrer. For a complete maturation of raft, wait for $30 \mathrm{~min}$. The raft was removed from beaker containing SGF, washed three times with deionized water and placed in a centrifuge tube. The

Table 1. Composition of raft forming tablets

\begin{tabular}{|c|c|c|c|c|c|c|c|}
\hline Code & $\begin{array}{c}\text { Sodium alginate } \\
(\%)\end{array}$ & $\begin{array}{l}\text { Pectin } \\
(\%)\end{array}$ & $\begin{array}{c}\text { HPMC K100M } \\
(\%)\end{array}$ & $\begin{array}{l}\mathrm{NaHCO}_{3} \\
(\%)\end{array}$ & $\begin{array}{c}\text { Citric acid } \\
(\%)\end{array}$ & $\begin{array}{c}\text { Calcium carbonate } \\
(\%)\end{array}$ & $\begin{array}{c}\text { Total weight } \\
(\%)\end{array}$ \\
\hline $\mathrm{R} 1$ & 27.50 & 10.00 & 14.00 & 18.00 & 9.00 & 6.50 & 100 \\
\hline $\mathrm{R} 2$ & 27.50 & 27.50 & 10.00 & 14.00 & 7.00 & 4.00 & 100 \\
\hline R3 & 2.50 & 2.50 & 10.00 & 40.00 & 20.00 & 15.00 & 100 \\
\hline $\mathrm{R} 4$ & 10.00 & 27.50 & 14.00 & 20.00 & 10.00 & 3.50 & 100 \\
\hline R5 & 2.50 & 10.00 & 6.00 & 40.00 & 20.00 & 6.50 & 100 \\
\hline R6 & 27.50 & 2.50 & 10.00 & 30.00 & 15.00 & 5.00 & 100 \\
\hline R7 & 2.50 & 27.50 & 10.00 & 30.00 & 15.00 & 5.00 & 100 \\
\hline R8 & 27.50 & 10.00 & 6.00 & 25.00 & 12.50 & 4.00 & 100 \\
\hline R9 & 10.00 & 10.00 & 10.00 & 30.00 & 15.00 & 5.00 & 100 \\
\hline R10 & 10.00 & 2.50 & 6.00 & 40.00 & 20.00 & 6.50 & 100 \\
\hline R11 & 10.00 & 10.00 & 10.00 & 60.00 & 15.00 & 5.00 & 100 \\
\hline R12 & 10.00 & 10.00 & 10.00 & 60.00 & 15.00 & 5.00 & 100 \\
\hline R14 & 10.00 & 10.00 & 10.00 & 30.00 & 15.00 & 5.00 & 100 \\
\hline R15 & 10.00 & 27.50 & 6.00 & 25.00 & 12.50 & 4.00 & 100 \\
\hline R16 & 2.50 & 10.00 & 14.00 & 35.00 & 17.50 & 6.00 & 100 \\
\hline R17 & 10.00 & 10.00 & 10.00 & 30.00 & 15.00 & 5.00 & 100 \\
\hline
\end{tabular}




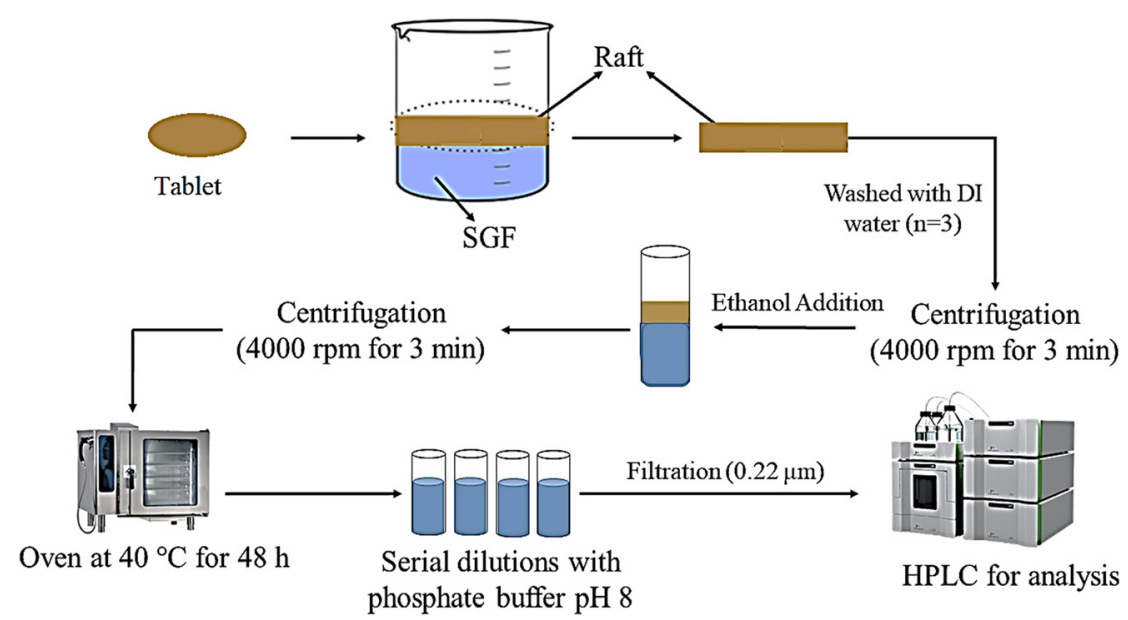

Fig. 2. Schematic representation for the estimation of sodium alginate and pectin in raft forming tablets

centrifuge tube, containing deionized water at $40{ }^{\circ} \mathrm{C}$, was stirred at $250 \mathrm{rpm}$ for $1 \mathrm{~min}$. Then, the tube was centrifuged for $3 \mathrm{~min}$ at 5,000 rpm, the supernatant was removed and the procedure was repeated twice. Ethanol was added to each centrifuge tube at $4{ }^{\circ} \mathrm{C}$ and the tubes were again centrifuged at $5,000 \mathrm{rpm}$ for $3 \mathrm{~min}$. Finally, the raft was removed from the tube and dried in an oven at $40{ }^{\circ} \mathrm{C}$ until constant weight, after the rafts were weighed. HPLC, with an already developed method, was used to determine the content of alginate and pectin in the raft. A series of dilutions with a concentration of $0.2,0.4,0.6,0.8$ and $1 \mathrm{mg} / \mathrm{mL}$ of both sodium alginate and pectin were prepared with phosphate buffer having a $\mathrm{pH}$ 8.0. Each dilution was centrifuged at 5,000 rpm for $15 \mathrm{~min}$. The dried raft was grounded into a fine powder, dissolved in $5 \mathrm{ml}$ of phosphate buffer having a $\mathrm{pH} 8.0$, sonicated for $15 \mathrm{~min}$ at $37^{\circ} \mathrm{C}$ and then centrifuged for $5 \mathrm{~min}$ at $5,000 \mathrm{rpm}$. The raft solution was filtered through a $0.2 \mu \mathrm{m}$ syringe filter, while the first few drops of filtrate were discarded. The linear equation $\left(R^{2}=0.999\right)$ of a standard plot was used to determine the contents of sodium alginate and pectin present in the raft. Fig. 2 shows the schematic representation for the detection of sodium alginate and pectin in raft forming pharmaceuticals. The following equations were used to determine the contents of sodium alginate and pectin incorporated into the raft system.

$$
\begin{aligned}
& \text { Contents of sodium alginate }=(X m g / m l) \\
& \times \frac{V(m l) \times W_{1}(m g)}{W_{2}(m g)} \\
& \text { Contents of pectin }=(X m g / m l) \times \frac{V(m l) \times W_{1}(m g)}{W_{2}(m g)}
\end{aligned}
$$

The weight of alginate-pectin raft and sample were denoted by $W_{1}$ and $W_{2}$ respectively.

\section{RESULT AND DISCUSSION}

\section{Chromatographic method validation}

Analytical curve. The analytical curves for sodium alginate and pectin were linear over a range of $200-800 \mu \mathrm{g} / \mathrm{mL}$. For each concentration, three runs were applied and the graphs were plotted between the concentration and the area of the peak. The correlation coefficient $\left(R^{2}\right)$ for the standard of sodium alginate and pectin were found to be 0.9993 and 0.9991 respectively, as shown in Table 2. The ANOVA were applied to the regression data, the standard and prepared samples of sodium alginate and pectin showed 0.0012 and $0.025 P$-values indicated that the results were significant and showed a linear relationship. Oliveira et al. in 2019 studied the similar pattern of analytical curve for the combined estimation of two drugs in pharmaceuticals [9].

Specificity. The specificity of the method was analyzed and no interference from the polymeric materials (sodium alginate and pectin) was observed by performing separate injections of standard, placebo and polymeric samples respectively. The obtained results are in agreement with previously reported results by Habibi et al. in 2019 [10]. The retention time of the sodium alginate and pectin were 3.931 and 7.470 min respectively, as shown in Fig. 3.

\begin{tabular}{|c|c|c|c|c|}
\hline Drugs & Regression data & $R^{2}$ & $\begin{array}{c}\text { LOD } \\
(\mu \mathrm{g} / \mathrm{mL})\end{array}$ & $\begin{array}{c}\text { LOQ } \\
(\mu \mathrm{g} / \mathrm{mL})\end{array}$ \\
\hline \multicolumn{5}{|l|}{ Standards } \\
\hline $\begin{array}{l}\text { Sodium } \\
\text { alginate }\end{array}$ & $\begin{array}{c}y=(1.479 \pm \\
0.0157) \times- \\
(0.136 \pm 0.0146)\end{array}$ & 0.9991 & 2.331 & 2.981 \\
\hline Pectin & $\begin{array}{c}y=(0.168 \pm \\
0.0059) \times- \\
(0.056 \pm 0.0343)\end{array}$ & 0.9992 & 3.351 & 3.876 \\
\hline \multicolumn{5}{|l|}{ Sample } \\
\hline $\begin{array}{l}\text { Sodium } \\
\text { alginate }\end{array}$ & $\begin{array}{c}y=(0.576 \pm \\
0.0137) \times- \\
(0.069 \pm 0.0236)\end{array}$ & 0.9993 & 2.443 & 3.129 \\
\hline Pectin & $\begin{array}{c}y=(0.127 \pm \\
0.0237) \times- \\
(0.017 \pm 0.0330)\end{array}$ & 0.9991 & 3.126 & 3.785 \\
\hline
\end{tabular}

Table 2. Analytical curve and sensitivity data of sodium alginate and pectin in mobile phase 


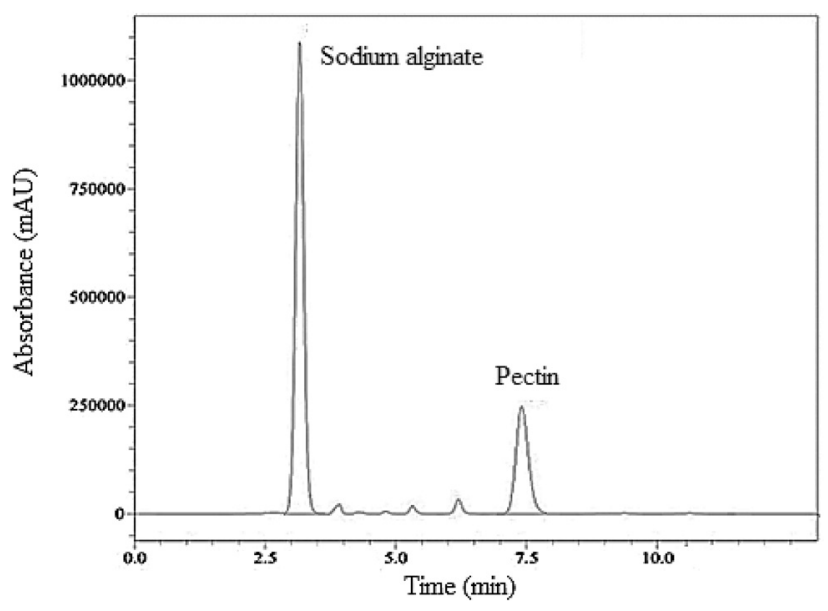

Fig. 3. Chromatogram showing sodium alginate and pectin peaks

Precision and accuracy. The accuracy of the procedure was established by repeating three concentrations (200, 400 and $600 \mu \mathrm{g} / \mathrm{mL}$ ) of sodium alginate and pectin in mobile phase at $378 \mathrm{~nm}$ and the percentage recoveries were calculated are shown in Table 3 . The percentage recovery of sodium alginate was ranged from 95.0 to $97.5 \%$. The pectin showed a percentage recovery between 94.7 and $96.5 \%$ as shown in Table 3. The precision of the developed method was tested by injecting three different concentrations of sodium alginate and pectin on the same day and the next three days. The inter-day and intra-day precision (RSD) of sodium alginate and pectin was calculated and shown in Table 3 . The RSD of sodium alginate and pectin were ranged from 1.3 to 1.9 and 1.2 to 1.9 as shown in Table 3. Li et al. in 2015 observed the inter-day and intra-day precision estimation of polymers and different other additives in different food additives by HPLC [11].

Detection and quantification limits. The LOD and LOQ were calculated by the sigma method. The LOD and LOQ of sodium alginate were found to be 2.443 and $3.129 \mu \mathrm{g} / \mathrm{mL}$ respectively, by injecting known concentrations of the sample. The LOD and LOQ of pectin were 3.126 and 3.785 $\mu \mathrm{g} / \mathrm{mL}$ respectively, as shown in Table 2 . Koppala et al. in 2016 observed the similar findings for LOD and LOQ for the combined monitoring of ketoprofen and omeprazole in pharmaceutical dosage forms [12].

System suitability parameters. The system suitability tests were analyzed by calculating the $\%$ RSD of sodium alginate in parameters such as theoretical plat, tailing factor, retention time, peak area and resolution were $0.015,1.96,0.030$, 0.001 and 1.325 respectively. The \% RSD of theoretical plates, tailing factor, retention time, peak area and resolution of the pectin were $0.34,1.08,0.67,2.9$ and 1.32 respectively. The retention time of sodium alginate and pectin was observed from chromatograms and it was found to be $3.12 \pm 0.5$ and $5.34 \pm 0.7 \mathrm{~min}$ respectively and are shown in Table 4. The resolution of sodium alginate and pectin was found in the range of $1.77-2.77$ and 5.10 to 5.41 respectively as shown in Table 4 . The resolution of 1 or higher represents an adequate separation of polymers [7]. Similarly, Zaman et al. in 2019 have developed method for the for the combined monitoring of drugs and their findings

Table 3. Within-day and Between-day precision of sodium alginate and pectin in mobile phase

\begin{tabular}{|c|c|c|c|c|c|c|}
\hline \multirow[b]{2}{*}{ Added $(\mu \mathrm{g} / \mathrm{mL})$} & \multicolumn{3}{|c|}{ Within-day $(n=6)$} & \multicolumn{3}{|c|}{ Between-day $(n=6)$} \\
\hline & Found $\pm \mathrm{SD}(\mu \mathrm{g} / \mathrm{mL})$ & $R S D$ & Recovery (\%) & Found $\pm \mathrm{SD}(\mu \mathrm{g} / \mathrm{mL})$ & $R S D$ & $\begin{array}{c}\text { Recovery } \\
(\%)\end{array}$ \\
\hline \multicolumn{7}{|l|}{ Sodium alginate } \\
\hline 200 & $195 \pm 0.44$ & 1.3 & 97.5 & $193 \pm 0.21$ & 1.4 & 96.5 \\
\hline 400 & $380 \pm 0.13$ & 1.9 & 95.0 & $378 \pm 0.14$ & 1.9 & 94.5 \\
\hline 600 & $575 \pm 0.45$ & 1.8 & 95.8 & $580 \pm 0.36$ & 1.5 & 96.6 \\
\hline \multicolumn{7}{|l|}{ Pectin } \\
\hline 200 & $193 \pm 0.31$ & 1.2 & 96.5 & $191 \pm 0.52$ & 1.9 & 95.5 \\
\hline 400 & $379 \pm 0.22$ & 1.6 & 94.7 & $381 \pm 0.35$ & 1.1 & 95.2 \\
\hline 600 & $573 \pm 0.46$ & 1.7 & 95.5 & $568 \pm 0.37$ & 1.3 & 94.6 \\
\hline
\end{tabular}

Table 4. System suitability parameters of sodium alginate and pectin in mobile phase

\begin{tabular}{lccccc}
\hline Parameters & Retention time $(\mathrm{min})$ & Peak area & Tailing factor & Theoretical plates & Resolution \\
\hline Sodium alginate & & & & & \\
Mean \pm SD & $3.93 \pm 0.5$ & 311,643 & 1.379 & 2,389 & 1.670 \\
RSD & 0.67 & 2.9 & 1.08 & 0.34 & -32 \\
Limits & - & $<2$ & $<2$ & - & $>1$ \\
Pectin & $7.44 \pm 0.7$ & 212,345 & 1.254 & 1,054 & 3.892 \\
Mean \pm SD & 2.31 & 1.97 & 1.07 & 0.05 & 1.54 \\
RSD & - & $<2$ & $<2$ & - & $>1$ \\
Limits & & & &
\end{tabular}


Table 5. Alginate contents within the alginate-pectin rafts of prepared formulations

\begin{tabular}{|c|c|c|c|c|c|}
\hline Code & $\begin{array}{c}\text { Pectin } \\
(\%)\end{array}$ & $\begin{array}{l}\text { Calcium } \\
\text { carbonate } \\
(\%)\end{array}$ & $\begin{array}{c}\text { Found } \\
\% \text { of SA }\end{array}$ & $\begin{array}{c}\% \\
\text { Recovery }\end{array}$ & $\begin{array}{c}\% \\
\text { RSD }\end{array}$ \\
\hline \multicolumn{6}{|c|}{ Formulation containing maximum percentage of (27.5\%) SA } \\
\hline $\mathrm{R} 1$ & 10.00 & 6.50 & 26.50 & 96.36 & 0.897 \\
\hline $\mathrm{R} 2$ & 27.50 & 8.00 & 23.50 & 84.45 & 1.675 \\
\hline R6 & 2.50 & 10.00 & 24.55 & 89.27 & 1.340 \\
\hline R8 & 10.00 & 8.00 & 19.55 & 71.09 & 0.91 \\
\hline \multicolumn{6}{|c|}{ Formulation containing medium percentage of (10\%) SA } \\
\hline $\mathrm{R} 4$ & 27.50 & 7.00 & 7.05 & 70.50 & 0.357 \\
\hline R9 & 10.00 & 10.00 & 9.92 & 99.20 & 1.209 \\
\hline $\mathrm{R} 10$ & 2.50 & 13.00 & 7.41 & 74.10 & 1.23 \\
\hline R11 & 10.00 & 10.00 & 9.25 & 92.50 & 0.786 \\
\hline R12 & 10.00 & 10.00 & 8.81 & 88.10 & 0.903 \\
\hline $\mathrm{R} 13$ & 2.50 & 12.00 & 7.95 & 79.50 & 0.675 \\
\hline R14 & 10.00 & 10.00 & 7.91 & 79.10 & 0.24 \\
\hline R15 & 27.50 & 8.00 & 9.34 & 93.40 & 1.320 \\
\hline R17 & 10.00 & 10.00 & 9.55 & 90.50 & 1.190 \\
\hline \multicolumn{6}{|c|}{ Formulation containing minimum percentage of (2.5\%) SA } \\
\hline R3 & 2.50 & 30.00 & 1.81 & 72.40 & 0.786 \\
\hline R5 & 10.00 & 13.00 & 2.22 & 88.80 & 1.674 \\
\hline R7 & 27.50 & 10.00 & 1.95 & 78.00 & 1.456 \\
\hline R16 & 10.00 & 12.00 & 1.82 & 72.80 & 0.90 \\
\hline
\end{tabular}

for system suitability was similar to the findings of this research article [13].

Alginate and pectin contents in raft forming tablets. The contents of alginate and pectin present in the raft were evaluated and are presented in Table 5 and 6 . The

Table 6. Pectin contents within the alginate-pectin rafts of prepared formulations

\begin{tabular}{|c|c|c|c|c|c|}
\hline Code & $\begin{array}{l}\text { SA } \\
(\%)\end{array}$ & $\begin{array}{c}\text { Calcium } \\
\text { carbonate } \\
(\%)\end{array}$ & $\begin{array}{l}\text { Found } \% \\
\text { of pectin }\end{array}$ & $\begin{array}{c}\% \\
\text { Recovery }\end{array}$ & $\begin{array}{c}\% \\
\text { RSD }\end{array}$ \\
\hline \multicolumn{6}{|c|}{ Formulation containing maximum percentage of (27.5\%) Pectin } \\
\hline R2 & 27.50 & 8.00 & 21.80 & 79.27 & 1.367 \\
\hline $\mathrm{R} 4$ & 27.50 & 7.00 & 16.50 & 60.00 & 0.987 \\
\hline R7 & 2.50 & 10.00 & 17.70 & 64.36 & 1.564 \\
\hline R15 & 10.00 & 8.00 & 25.50 & 92.72 & 0.924 \\
\hline \multicolumn{6}{|c|}{ Formulation containing medium percentage of (10\%) Pectin } \\
\hline $\mathrm{R} 1$ & 27.50 & 13.00 & 9.40 & 94.00 & 1.982 \\
\hline R5 & 2.50 & 13.00 & 8.50 & 85.00 & 1.564 \\
\hline $\mathrm{R} 8$ & 27.50 & 8.00 & 6.20 & 62.00 & 1.290 \\
\hline R9 & 10.00 & 10.00 & 9.72 & 97.20 & 0.568 \\
\hline R11 & 10.00 & 10.00 & 8.50 & 85.00 & 0.398 \\
\hline R12 & 10.00 & 10.00 & 8.10 & 81.00 & 1.276 \\
\hline R14 & 10.00 & 10.00 & 7.20 & 72.00 & 1.076 \\
\hline R16 & 2.50 & 12.00 & 6.90 & 69.00 & 0.598 \\
\hline R17 & 10.00 & 10.00 & 8.50 & 85.00 & 0.367 \\
\hline \multicolumn{6}{|c|}{ Formulation containing minimum percentage of (2.5\%) Pectin } \\
\hline R3 & 2.50 & 30.00 & 1.59 & 63.60 & 0.912 \\
\hline R6 & 27.50 & 10.00 & 2.03 & 81.20 & 1.786 \\
\hline R10 & 10.00 & 13.00 & 1.57 & 62.80 & 0.786 \\
\hline R13 & 10.00 & 12.00 & 1.78 & 71.20 & 1.087 \\
\hline
\end{tabular}

formulations (R1, R2, R6 and R8) contained a maximum percentage of SA i.e. $27.5 \%$ but different concentrations of pectin and calcium carbonate presented 71.09-96.36\% percentage recovery of SA and \% RSD was ranged from 0.897 to 1.675 as displayed in Table 5 . The recovery rates of R4, R9, R10, R11, R12, R13, R14, R15 and R17 contained $10 \%$ SA (medium concentration) ranged from 70.50 to $99.20 \%$ and $\%$ RSD was less than $2 \% .72 .40-88.80 \%$ percentage recoveries of SA were obtained from raft of R3, R5, R7 and R16 formulations contained $2.5 \%$ of SA and \% RSD was ranged from 0.786 to 1.674 . The formulations (R2, R2, R7 and R15) contained maximum percentage of pectin i.e. $27.5 \%$ but different concentrations of SA and calcium carbonate showed $60.00-92.72 \%$ percentage recoveries of pectin and \% RSD was ranged from 0.924 to 1.564 as shown in Table 6. The formulations R1, R5, R8, R9, R11, $\mathrm{R} 12, \mathrm{R} 14, \mathrm{R} 16$ and $\mathrm{R} 17$ contained $10 \%$ pectin showed percentage recoveries of pectin ranged from 62.00 to $97.20 \%$ and \% RSD was less than $2 \%$. The $62.80-81.20 \%$ percentage recoveries of pectin were obtained from raft of $\mathrm{R} 3, \mathrm{R} 6, \mathrm{R} 10$ and $\mathrm{R} 13$ formulations contained $2.5 \%$ of pectin and \% RSD was ranged from 0.786 to 1.786 . The alginatepectin raft of R9 formulation contained 99.20 and $97.20 \%$ alginate and pectin respectively. The chromatogram of R9 formulation showed the peaks of sodium alginate and pectin is shown in Fig. 4. The highest percentages of alginate and pectin were observed in formulation R9; this was due to the very compact nature of raft compared to other formulations. The lower percentages of alginate and pectin contents in alginate-pectin rafts were observed in the R4 formulation compared to the other formulations. Awad et al. in 2012 also studied the estimation of alginate in the pharmaceutical formulations by using HPLC [3]. The presence of alginate and pectin in the raft is important for trapping antacids in the raft that constitute a neutral barrier of gastric acidity into the esophagus. The presence of alginate and pectin in the raft affects the strength and integrity of the raft and also allows the raft to trap an antacid in the gel.

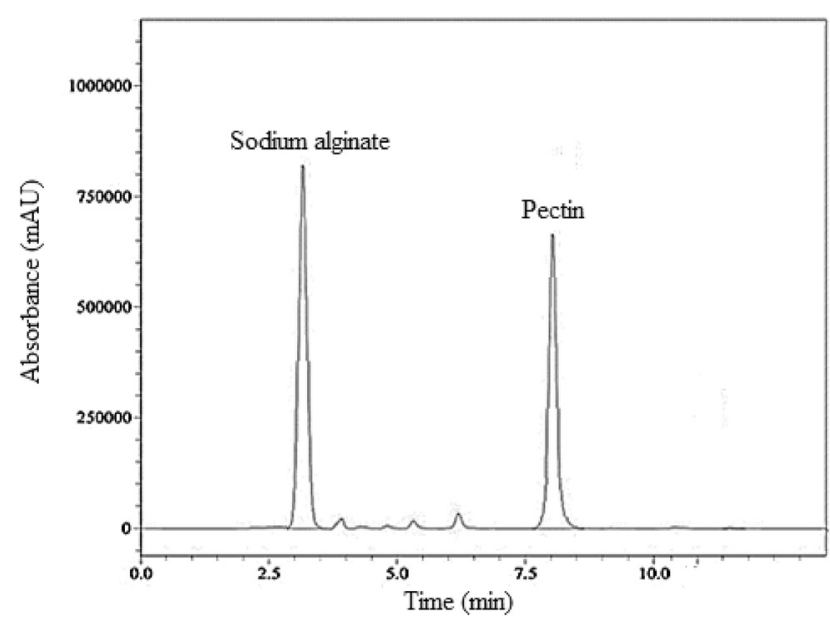

Fig. 4. Chromatogram of R9 formulation showing peaks of sodium alginate and pectin 


\section{CONCLUSION}

The proposed method was simple, precise, sensitive and inexpensive for the combined monitoring of sodium alginate and pectin in raft forming drug delivery systems. The method was validated over a concentration range of 200-800 $\mu \mathrm{g} / \mathrm{mL}$ and had good accuracy and precision. The developed HPLC method was found to be highly precise, sensitive, inexpensive and accurate for the determination of sodium alginate and pectin. This method is quite useful and reasonably meets all standards.

\section{REFERENCES}

1. Abbas, G.; Hanif, M.; Khan, M. A. Des. Monomers Polym. 2017, 20, $1-9$.

2. Abbas, G.; Hanif, M. J. Appl. Polym. Sci. 2017, 134, 44442-50.

3. Awad, H.; Aboul-Enein, H. Y. J. Chromatogr. Sci. 2012, 51, 208-14.
4. Scherer, R.; Rybka, A. C. P.; Ballus, C. A.; Meinhart, A. D.; Teixeira Filho, J.; Godoy, H. T. Food Chem. 2012, 135, 150-4.

5. Naidu, K. R.; Kale, U. N.; Shingare, M. S. J. Pharm. Biomed. Anal. 2005, 39, 147-55.

6. Peng, L.; Song, X.; Shi, X.; Li, J.; Ye, C. J. Food Compos. Anal. 2008, 21, 559-63.

7. Sungthong, B.; Rattarom, R.; Sato, V. H.; Sato, H. Acta Chromatogr. 2019, 31, 241-5.

8. Abbas, G.; Hanif, M. Drug Dev. Ind. Pharm. 2018, 44, 2026-37.

9. Oliveira, K. R. W.; Sversut, R. A.; Singh, A. K.; Amaral, M. S.; Kassab, N. M. Acta Chromatogr. 2019, 31, 291-3.

10. Habibi, B.; Ghorbel-Abid, I.; Lahsini, R.; Ben Hassen, D. C.; Trabelsi-Ayadi, M. Acta Chromatogr. 2019, 31, 109-12.

11. Li, B.; Wang, Z.-W.; Lin, Q. B.; Hu, C. Y.; Su, Q. Z.; Wu, Y. M. J. Chromatogr. Sci. 2015, 53, 1026-35.

12. Koppala, S.; Ranga reddy, V.; Anireddy, J. S. J. Chromatogr. Sci. 2016, 54, 765-75.

13. Zaman, M.; Hanif, M.; Khan, N. U. H.; Mahmood, A.; Qaisar, M. N.; Ali, H. Acta Chromatogr. 2019, 31, 173-8. 